\title{
Wedge equilibrium in fold-and-thrust belts: prediction of out-of-sequence thrusting based on sandbox experiments and natural examples
}

\author{
D.A. Nieuwland ${ }^{1}$, J.H. Leutscher ${ }^{2} \&$ J. Gast ${ }^{3}$
}

1 corresponding author; Shell International E \& P, Research and Technical Services, Volmerlaan 6-8, 2288 GD, RIJSWIJK, the Netherlands; present address:Vrije Universiteit, de Boelelaan 1085, 1081 HV AMSTERDAM, the Netherlands; e-mail: nied@geo.vu.nl

2 Geology Dept. Utrecht University, UTRECHT, the Netherlands; present address: Agip Norway, P.O. Box 101, N-4033 Forus, Norway

3 Geology Dept. Utrecht University, UTRECHT, the Netherlands; present address: Nederlandse Aardolie Maatschappij, VELZEN, the Netherlands

Manuscript received: December 1997; accepted in revised form: December 1999

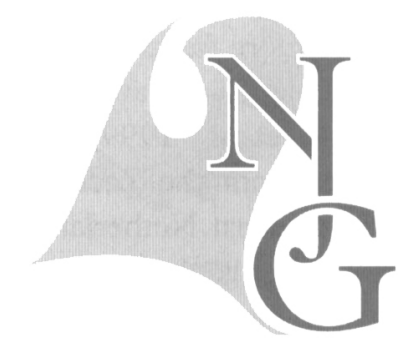

\begin{abstract}
Thrust tectonics are dealt with on the basis of primarily experiments focusing on the dynamics of a developing thrust belt and on understanding and predicting normal-sequence and out-of-sequence thrusting. Field examples are presented in addition to the examples of sandbox-model experiments. The results have improved the insight into thrust-belt-forming mechanisms; the validity of the conclusions is supported by natural examples.

The experimental program was aimed at examining the effect of changes in a selection of key parameters in thrust tectonics on the geometry and the successive phases in the development of thrust sheets. Sandbox experiments were used to analyse the effects of basal friction, detachment lithology, basement relief and syntectonic sedimentation. Multilayer experiments were performed to simulate the effects of ductile detachment lithologies.

It was found that a thrust belt's cross-sectional geometry is formed in a dynamic process during which the wedge may develop from subcritical through critical to supercritical and back to critical again. The process is illustrated with sandbox experiments, analysed by time-lapse computed tomography scans and in-situ stress measurements. On the basis of the sandboxmodel results and the natural examples, we conclude that a critical examination of the boundary conditions of a fold-andthrust belt and of changes in these conditions during the deformation process enables predictions about the geometry and kinematics of the thrust belt.
\end{abstract}

Keywords: brittle behaviour, critical taper, ductile behaviour, geometry, kinematics, thrust tectonics

\section{Introduction}

The present contribution is based on part of an experimental study of thrust tectonics. Two main questions were examined: what controls the $3-\mathrm{D}$ internal and external geometry of individual thrust sheets, and what influences the dynamics of thrusting? The dynamics of a developing thrust belt are the main topic studied here, with the objective of obtaining a better understanding and a possibility of more reliable predicting of normal-sequence and out-of-sequence thrusting. Field examples of out-of sequence thrusting are incorporated together with sandbox-model experiments. The sandbox models were all performed on a horizontal base, which oversimplifies the natural situation in which a basement commonly dips towards the hinterland.

"As in so many problems in structural geology, the key lies in a proper deciphering of the geometry and the sequences of structural events" (Elliot, 1976). An understanding of the controlling parameters responsible for the wide variation of structural styles in thrust tectonics is of considerable help in the interpretation of seismic data, which - in thrust belts - are often of poor to moderate quality. Accurate descriptions of regional cross-sections and outcrop examples refer to the static end product of a dynamic process; they are therefore necessary but not sufficient for this understanding. Thrust belts are the result of a combination of processes and consequently 
of variations in boundary conditions throughout their formation. It is therefore necessary to study key parameters that govern the structural development, using an experimental modelling approach in which one parameter at the time can be varied. An additional advantage of experimental modelling is that the process of overthrusting can be seen to take place, and that the investigator is not limited to studying the static end product.

The effect of changing the basal friction of a moving thrust wedge has been modelled numerically by Willett (1992). The present study deals with the dynamics of a moving wedge with fixed and with varying boundary conditions. The experimental program was aimed at examining the effect of changes in a selection of key parameters (boundary conditions) in thrust tectonics on the geometry and the sequence of development of thrust sheets. Sandbox experiments were used to analyse the effects of basal friction, detachment lithology, basement relief and syntectonic sedimentation. In addition to experiments carried out with sand only, multilayer experiments were performed, resulting in realistic, complex, multilayer fold-and-thrust models. The modelling techniques that were used apply to the upper, brittle part of the crust and were not intended to model the metamorphic domain, although many of the principles discussed here also apply to higher-grade metamorphic rocks during deformation. X-ray computed tomography (CT) scanning has been used in combination with $3-D$ visualisation to study the sandbox experiments in space and in time. Typical geometrical elements that have been studied in relation to the varying parameters are: thrust-sheet length, dip of the fault plane (ramp), curvature of the fault plane, frequency of backthrusting, and out-of-sequence thrusting.

Thrust belts are dynamic rather than static systems; their stresses and resulting strains reflect a dynamic equilibrium. In general, the formation of a fold-and-thrust belt begins with the formation of a critical taper (or wedge) (Davis et al., 1984; Suppe, 1985; Huiqi et al., 1991) (the terms 'wedge' and 'taper' will be used as synonyms throughout the present contribution). Once the taper has reached its critical angle, a normal piggyback sequence of thrusting, propagating towards the foreland, will start (Mandl \& Shippam, 1981; Mandl, 1988). A stable geometry exists for each given combination of boundary conditions. This geometry is achieved in a dynamic process during which the wedge may develop from subcritical through critical to supercritical and back to critical again. A supercritical wedge is steeper and a subcritical wedge is less steep than the ideal angle would be. Deviation from equilibrium conditions for the critical taper will result in out-of-sequence thrusting (if the new equilibrium requires a steeper taper) or in extensional deformation (if the new equilibrium requires a flatter taper; Willett, 1992). Such a deviation is commonly the result of changes from low to high basal friction (requiring an increased wedge angle) and of syntectonic sedimentation (this reduces the taper angle and requires the taper to build up in order to increase the angle again). It can also be the result of a reduction in basal friction (the taper needs to become flatter). Before discussing the predictive aspects of the dynamic-equilibrium concept, the most important controlling parameters in thrust tectonics and their effects on the geometry and the kinematics will be examined.

Hardy et al. (1998) recently offered a theoretical mechanical model of the growth of the critical taper. The results of their theoretical model and the results of the analogue models presented here are in good agreement.

\section{General experimental configuration}

The general configuration of the sandbox experiments was a sand pack of $3-4 \mathrm{~cm}$ thick, uniformly shortened by displacement of a horizontally moving vertical backstop. The material on which the sand pack was sliding, was varied according to the type of friction to be modelled. High friction was achieved by glueing sand to the base plate. For low friction, a smooth PVC plate was used. An elasto-plastic very low-friction decollement was modelled by an oil/ water emulsion (OWE), a visco-plastic very low-friction decollement was simulated by using silicone putty (SP) (Figure 1; Verschuren et al., 1996). All models initially develop a wedge immediately next to the backstop. Once the taper has reached its critical angle, thrusts propagate further forward into what has been defined as foreland for the purpose of our experiment description.

A natural equivalent of the elasto-plastic material is soft clay; that of the visco-plastic material is salt.

\section{Basal frictional resistance}

The effect of basal friction was studied for both the detachment phase and the overthrust phase. The wedge equilibrium and out-of-sequence thrusting were also studied.

\section{The effect of basal friction during the detachment phase}

Basal friction is probably the most important single factor governing the geometry and structural style of 

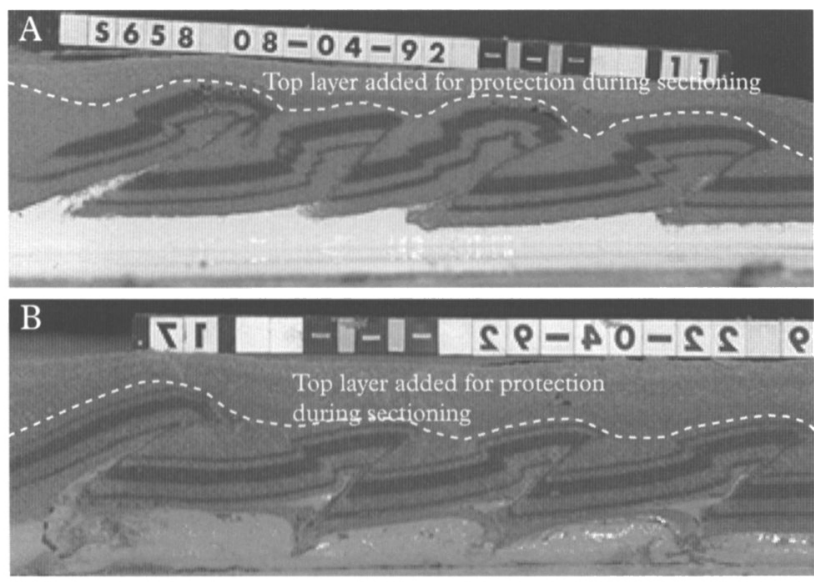

Fig. 1. Sandbox models with horizontal layers of $2 \mathrm{~cm}$ of sand on 1 $\mathrm{cm}$ of ductile material. Shortening was by a vertical backstop at 2 $\mathrm{cm}$ per hour from left to right (bottom picture has been flipped for consistency of view). The top layer was added after the deformation to protect the structure of the model during wetting and slicing. The thrusts young towards the right (foreland). The viscous behaviour of the SP allows for vertical movement of the thrust sheets after formation of a new ramp; this requires only one antithetic backthrust, as opposed to the many backthrusts required with the nonviscous OWE detachment.

A: section of an experiment with an oil/water emulsion (OWE) as ductile detachment.

B: section of an experiment with silicone putty (SP) as a ductile and viscous detachment.

a thrust complex. In nature, it varies considerably depending on the decollement, which may vary from relatively high-resistive normally pressured shales, to very low-resistive rocks such as rock salt or overpressurized clay. Very long thrust sheets can develop within relatively high-friction rocks if high fluid pressures
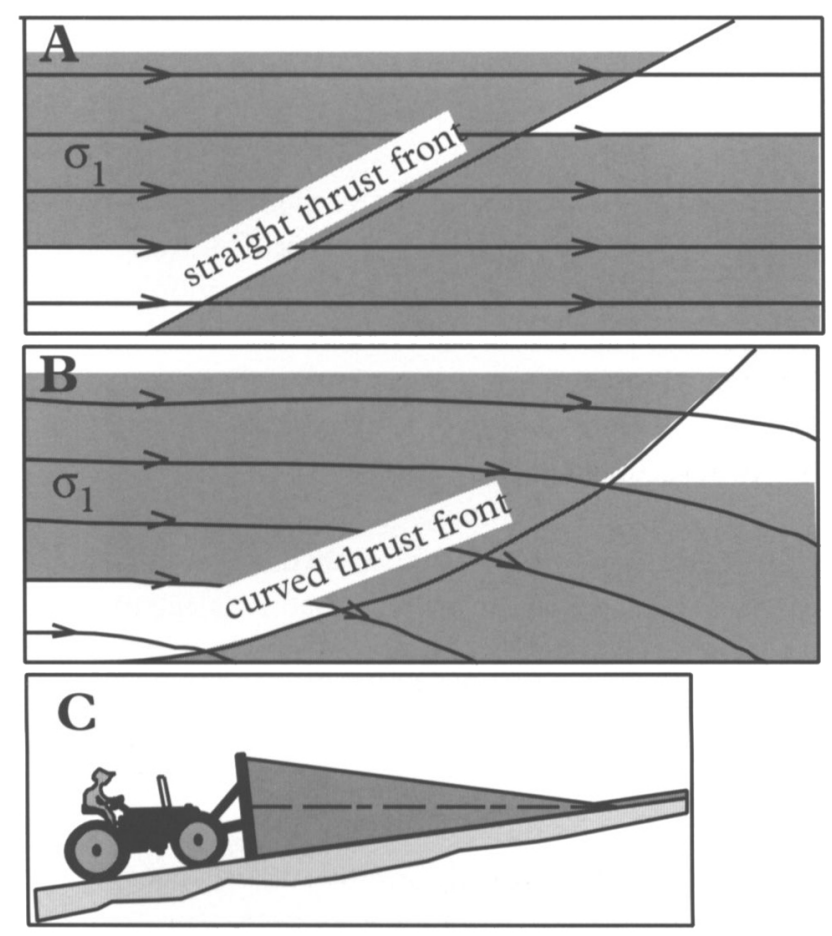

are generated on which thrust-sheet gliding can take place. Consider the formation of a thrust fault in the case of horizontal compression. Theoretically, the fault zone - being a Coulomb slip plane, has a fixed angular relationship of $45^{\circ}$ for $\phi / 2$ and $\sigma_{1}$, in which $\phi$ is the angle of internal friction and $\sigma_{1}$ the maximum principal stress. In the case of thrust tectonics, $\sigma_{1}$ is horizontal, whereas the minimum principal stress, $\sigma_{3}$, is vertical. Consequently, when the basal frictional resistance is low or absent, the orientation of $\sigma_{1}$ is not affected by a shear-stress component along the detachment. It remains horizontal and the frontal ramp develops as a straight flat plane, dipping at approximately $30^{\circ}$ to the horizontal (Fig. 2a) (Jaeger \& Cook, 1979; Mand1 \& Shippam, 1981; Mandl, 1988). In contrast, when the basal friction is high, the basal shear stress forces the main compressive stress, $\sigma_{1}$, to rotate towards the detachment plane, gradually rotating back to horizontal higher in the section (Fig. 2b). Consequently, the resulting thrust plane curves upward (Fig. 2b). A brittle thrust sheet on a low-friction decollement that is being pushed across a straight flat onto a straight ramp, has to move past an abrupt kink. The resulting internal deformation needs to be accommodated. This can be achieved by bedding-plane slip, by backthrusting, or by a combination of both. With very low friction and a very sharp kink, bedding-plane slip alone is not sufficient and antithetic backthrusting is always required. In contrast, a brittle thrust sheet moving on a high-friction decollement over a curved ramp, requires less deformation to accommodate the internal strain. High basal friction is

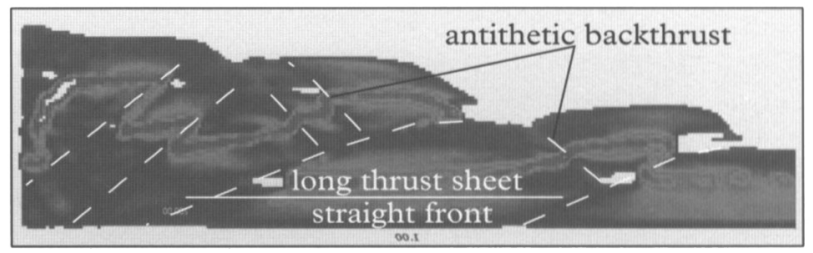

CT scan of sandbox model with low basal friction,

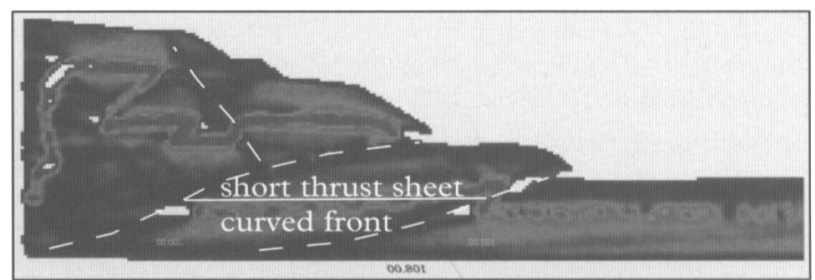

CT scan of sandbox model with high basal friction.

Fig. 2. Summary of basic mechanics and geometric characteristics (Davis et al., 1984). Low basal friction without basal shear stress results in a straight thrust front dipping at about $30^{\circ}$. With high basal friction, the basal shear stress results in a curved thrust front. The taper resembles the buldozer principle. A pile of snow or earth pushed in front of a buldozer follows the same mechanics as a developing thrustbelt with a critical taper in front of the indenter. 
therefore associated with short thrust sheets, a curved ramp and a general lack of backthrusting (Fig. 3b), whereas low basal friction is associated with long thrust sheets, a straight ramp and backthrusting (Fig. $3 c)$.

\section{The effect of basal friction in the overthrust phase}

The effect of basal friction persists with continued deformation and expresses itself also on a larger scale in the geometry of the thrust belt (Mitra, 1986; Mitra \& Boyer, 1986; Moore 1989). Consider the effect of increasing basal friction on thrust-sheet length. The critical angle of the taper increases with increasing basal friction. With very low basal friction, the length of individual sheets is greater than the displacement
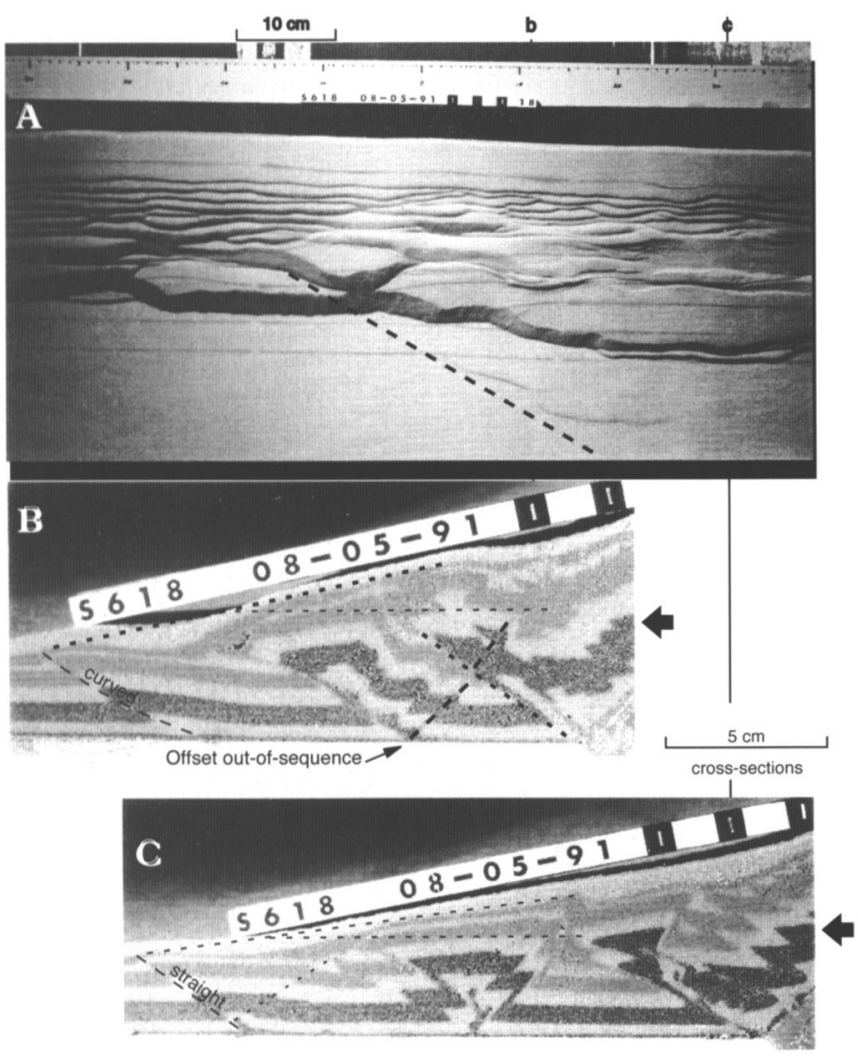

Fig. 3. Top view and cross-sections of experiment $5618 ; 3-\mathrm{cm}$ sandpack, $25-\mathrm{cm}$ shortening from low to high friction across a diagonal boundary.

A: the thrust front reflects the diagonal boundary between the lowfriction and the high-friction zones as it recedes towards the highfriction side of the model.

B: cross-section across the low-friction to high-friction boundary. The older thrusts are straight, associated with antithetic backthrusts. The frontal thrust on the high-friction base is curved; no backthrust was formed. The angle of the taper has steepened relative to the angle in section $C$.

$\mathrm{C}$ : a cross-section in the low-friction zone; the last increment of movement over high-friction caused some out-of-sequence thrusting to adjust the angle of the taper. The uppermost dark layer and the light one above it have been added after the deformation in order to protect the model during wetting and sectioning. of each thrust sheet and the resulting geometry is that of a series of individual ramp anticlines (Figs. 1b, 6a, $6 \mathrm{~b})$. With increasing basal friction, the length of the thrust sheets decreases relative to the displacement and the geometry gradually evolves from a duplex to that of an anticlinal stack (Figs. 1, 3, 5; Mitra, 1986).

\section{Wedge equilibrium and out of-sequence thrusting}

With constant boundary conditions (i.e., without changes in basal friction), a thrust belt develops in a 'piggy-back' mode. This process has been examined in a series of sandbox experiments which was sampled with time-lapse CT scans (Figs. 4, 5). The wedge angle can be measured as soon as a minimum of two thrusts has formed (as one thrust only gives the angle of repose of the sand). New thrusts form in front of existing ones, and the existing thrusts ride passively on the back of the latest thrust sheet without further internal deformation. The series shows that the wedge moves stable until the moment that the third thrust begins to form; the wedge angle then increases temporarily from $11^{\circ}$ to $14.5^{\circ}$ and decreases again to $11^{\circ}$ once the third thrust has formed and the system becomes stable again. This observation is in line with the horizontal stress development as measured in sandbox experiments of thrust tectonics (Fig. 4; Nieuwland et al., 1999). The in-situ stress measurements show that the horizontal stress increases sharply just before a new thrust fault begins to form and decreases almost instantly once the new thrust breaches the surface. During the stress increase, the balance of forces in the taper changes and the taper becomes supercritical $\left(14.5^{\circ}\right)$. As soon as the horizontal stress is back to the level of the early overthrust phase, the wedge returns to the normal equilibrium angle (in this example $11^{\circ}$ ).

When the boundary conditions change during the thrusting process, the angle of the critical taper has to change accordingly. When the basal friction changes from low to high, the angle has to increase. A steeper taper is achieved by out-of-sequence thrusting, which may take place by either reactivation of existing faults or the generation of new thrusts, or by both. In general, changing the boundary conditions requires a new equilibrium geometry of the thrust wedge. Minor out-of-sequence thrusting is therefore a normal element in thrust-wedge development, but the stable wedge angle towards which the system converges remains unchanged.

The process of thrusting from low to high basal friction is demonstrated in Figure 5. As soon as the thrust front moves from the low-friction base to the high-friction base, the angle of the taper increases 


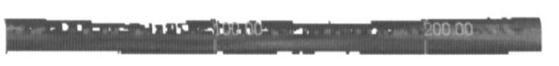

Deformation sequence: 0

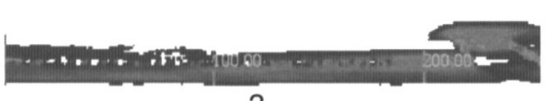

3

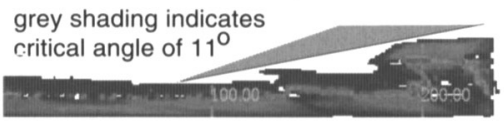

6

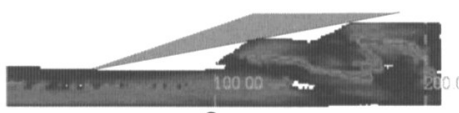

9

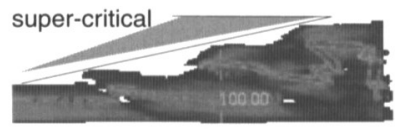

12

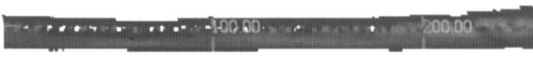

1
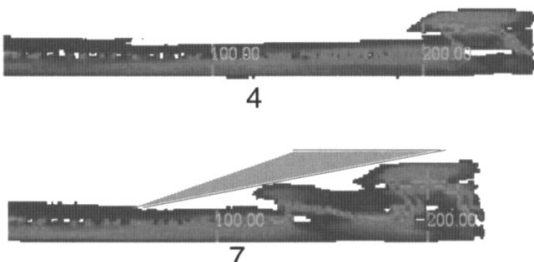

7

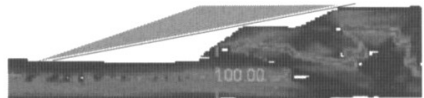

10

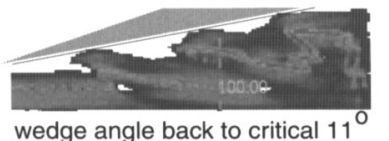

13

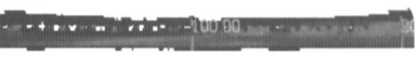

2
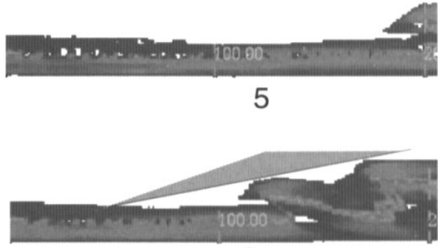

8

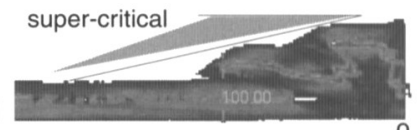

max angle during build-up is $14^{\circ}$

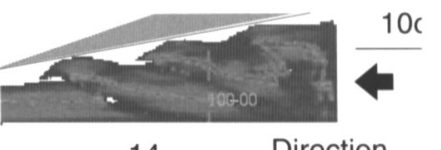

14 Direction

of compress

Fig. 4. Time-lapse VoxelView images from CT scans of a sandbox experiment with horizontal compression and high basal friction, showing the development of a piggy-back thrust sequence. The wedge angle develops to critical $\left(11^{\circ}\right)$, where it remains until the system becomes supercritical $\left(14.5^{\circ}\right)$ during the formation of the third thrust, whereafter the angle reduces to critical again. The thickness of the undeformed sandpack is $3 \mathrm{~cm}$.
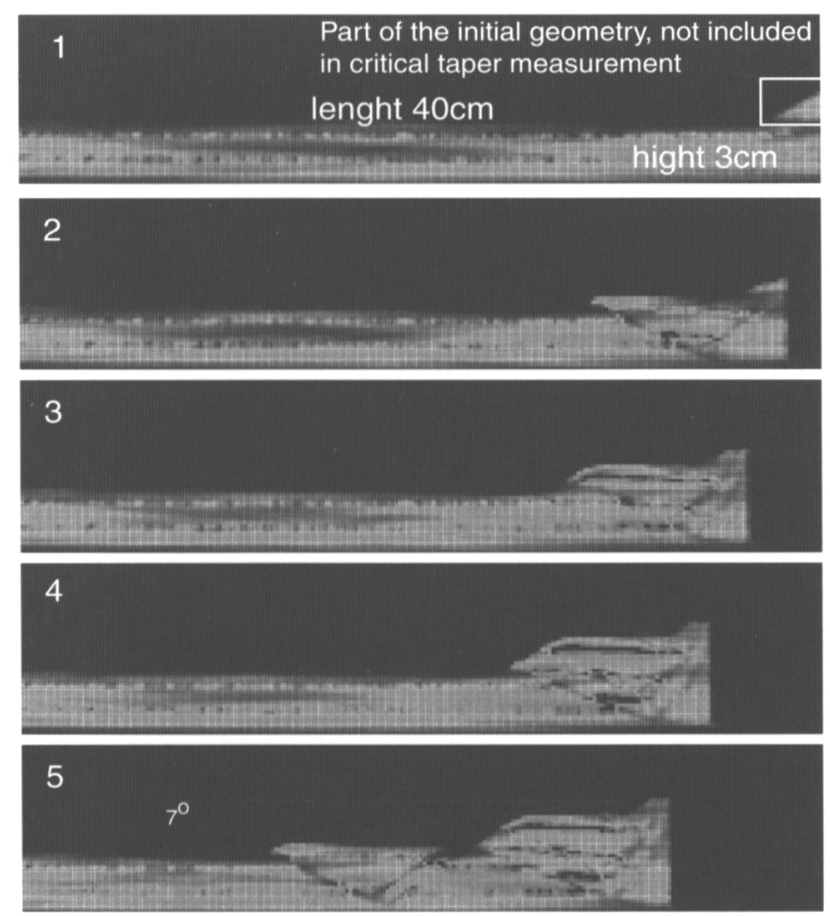
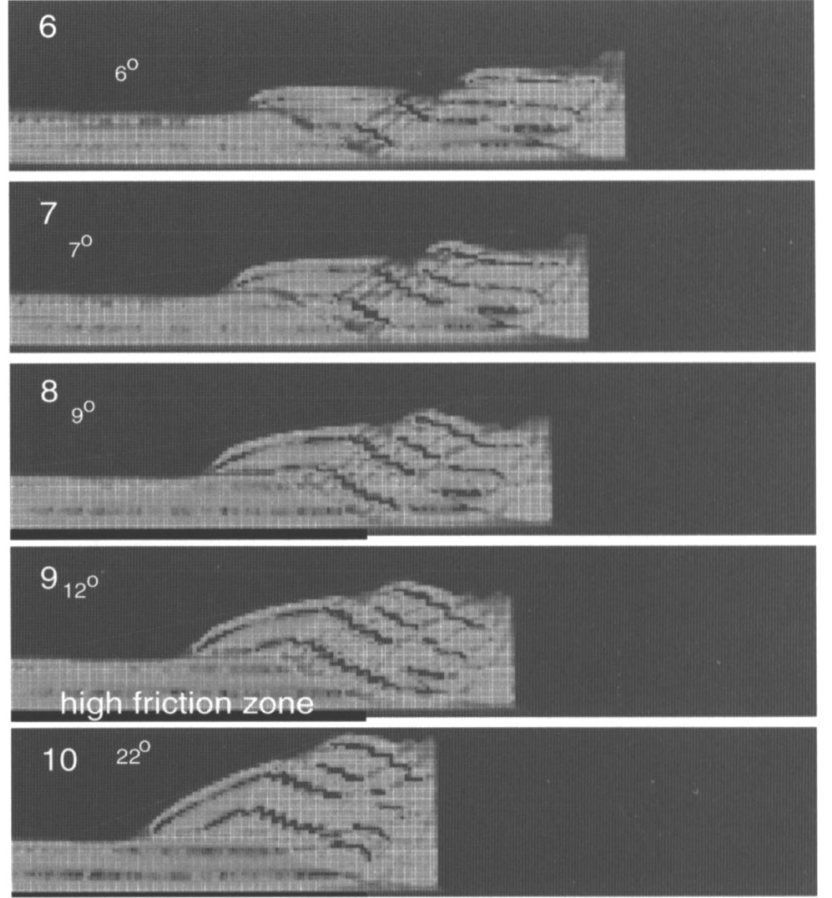

Fig. 5. The effect of increased basal friction on the angle of the critical taper is illustrated by a sandbox experiment. As soon as the thrust-belt front reaches the high-friction zone, the critical angle increases markedly.

1: the initial geometry is a $3-\mathrm{cm}$ thick sandpack with a small artificial wedge at the back of the model to gain space for shortening.

2: some lateral shortening and thickening of the sandpack, the first thrust develops, associated with an antithetic backthrust.

3: steady movement during the overthrust phase.

4: steady movement during the overthrust phase.

5: with two thrusts present, a critical angle can be measured.

6 : the $7^{\circ}$ angle reduces slightly due to rotation by the second thrust moving up the ramp.

7: as the system moves in steady state, the critical angle remains $7^{\circ}$.

8: the thrust belt front reaches the high basal-friction zone and the critical angle begins to increase.

9: the wedge angle is still subcritical and continues to increase by developing new antithetic backthrusts.

10: The wedge angle is still subcritical at 220 . The experiment had to be stopped at this stage to avoid edge effects due to proximity of the end of the sandbox. 
from $7^{\circ}$ to $22^{\circ}$. This is achieved by out-of-sequence internal deformation along existing thrusts. Natural examples from Romania and Albania demonstrate the effectiveness of the application of the concept of dynamic equilibrium of the critical taper (Figs. 7, 8; Stefanescu, 1984).

In Figure 3b, the earliest thrust cuts off the backthrust immediately in front of it. As this backthrust formed later than the first thrust, the latter must have been reactivated out of sequence. Note for comparison the backthrusts in the frontal thrust sheet in the time-lapse series of Figure 4, which have not been deformed.

\section{Basement highs}

Buried basement highs ahead of the thrust front concentrate the horizontal compressive stress and can therefore act as a nucleation site for thrust faulting. This can result in thrust sheets that are either shorter or longer than would normally be expected.

The presence of a basement high was modelled in 3-D by generating a normal fault in the basement with a $1-\mathrm{cm}$ throw, striking parallel to the advancing thrust front and perpendicular to the direction of shortening (Fig. 9). The length of the thrust sheet formed in this experiment is $19 \mathrm{~cm}$, significantly greater than the $13 \mathrm{~cm}$ normally reached for a $3-\mathrm{cm}$ thick sand pack with the same sand and the same boundary conditions, but with exception of the basement high (the length of a thrust sheet, $\mathrm{L}$, is the distance between two consecutive thrust planes, measured along a marker horizon in the undeformed state).

Following the formation of the footwall-shortcut thrust at the basement high, the earlier thrust was reactivated. This was the result of a change in the boundary conditions. The energy required to continue overthrusting of the exceptionally long thrust sheet over the basement high is more than is required for reactivation of the previous thrust (which is a plane of weakness) and for breaking up the very long thrust sheet. This results in reshaping of the critical taper by out-of-sequence thrusting.

Repeated experiments (five in total, sand only on a rigid base) confirmed that a basement high in the foreland acts as a location for thrust initiation (Fig. 9). When the basement high lies at a distance smaller than $\mathrm{L}$ from the hinterland, the length of the first thrust sheet will be less than $\mathrm{L}$, as the thrust fault is forced to form at the basement high. Also when the basement high in the foreland is located at a distance larger than $\mathrm{L}$ from the thrust front, however, the thrust is located at the basement high. The maximum possible increase in thrust sheet length in brittle rock depends on the frictional resistance at the decollement and on the strength of the thrust sheet rock. The length increases with decreasing friction:

$\mathrm{L}=\left(2 \mathrm{HC}_{0}+\rho \mathrm{gh}^{2}[\mathrm{~K}+\lambda(1-\mathrm{K})]\right) /\left[2 \tau_{0}+2 \mu_{\mathrm{f}}(1-\mathrm{f}) \rho \mathrm{gh}\right]$

where:

$\mathrm{L}=$ length of the thrust sheet

$\mathrm{H}=$ height of the thrust sheet

$\mathrm{C}_{0}=$ cohesion of the thrust sheet rock

$\rho=$ specific density of the thrust sheet rock

$\mathrm{g}=$ gravity constant

$\mathrm{K}=$ earth-pressure coefficient, $\left(\sigma_{1}-\mathrm{C}_{0}\right) / \sigma_{3}$

$\lambda_{\mathrm{f}}=$ fluid/pressure ratio: (pore-fluid pressure)/(lithostatic pressure)

$\tau_{0}=$ cohesive strength of the fault surface

$\mu_{\mathrm{f}}=$ coefficient of friction of the fault surface

Basically, this formula describes rock strength divided by basal friction (Suppe, 1985). It stands to reason that, beyond a certain distance from the thrust front, the effect of a basement high can no longer be felt. A formula to determine this distance has, to our knowledge, not yet been derived, neither theoretically nor experimentally.

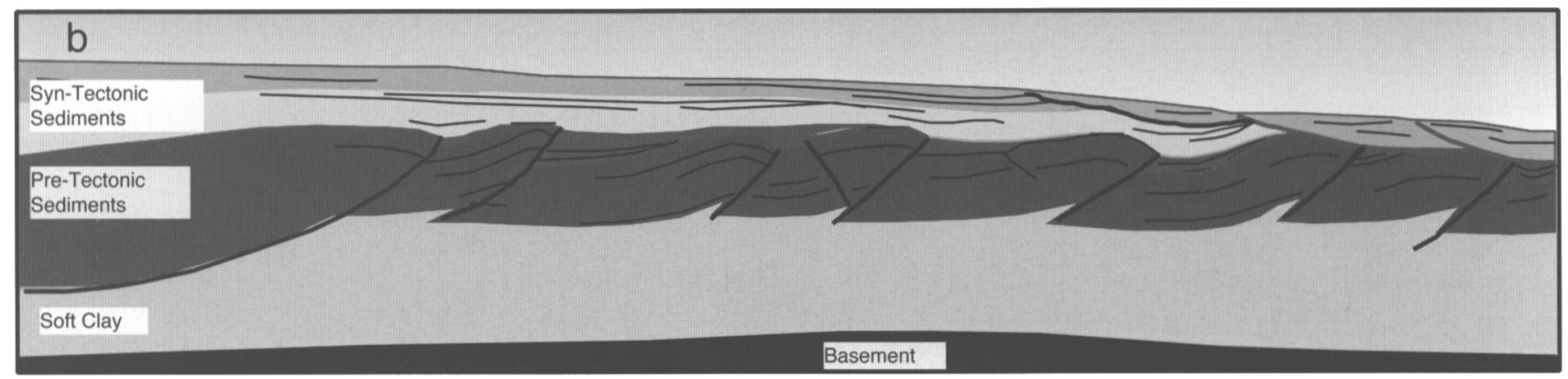

Horizontal scale appr. $10 \mathrm{~km}$; Vertical scale appr. 2 km.

Fig. 6. Interpretation of a seismic section of independent ramp anticlines, formed by thrusting of brittle clastic sediments over a weak decollement of ductile overpressured clay. The geometry resembles the experiments shown in figures $2 \mathrm{~B}$ and $3 \mathrm{C}$. Due to very low basal friction, the critical taper angle is very low (close to $0^{\circ}$ ). 


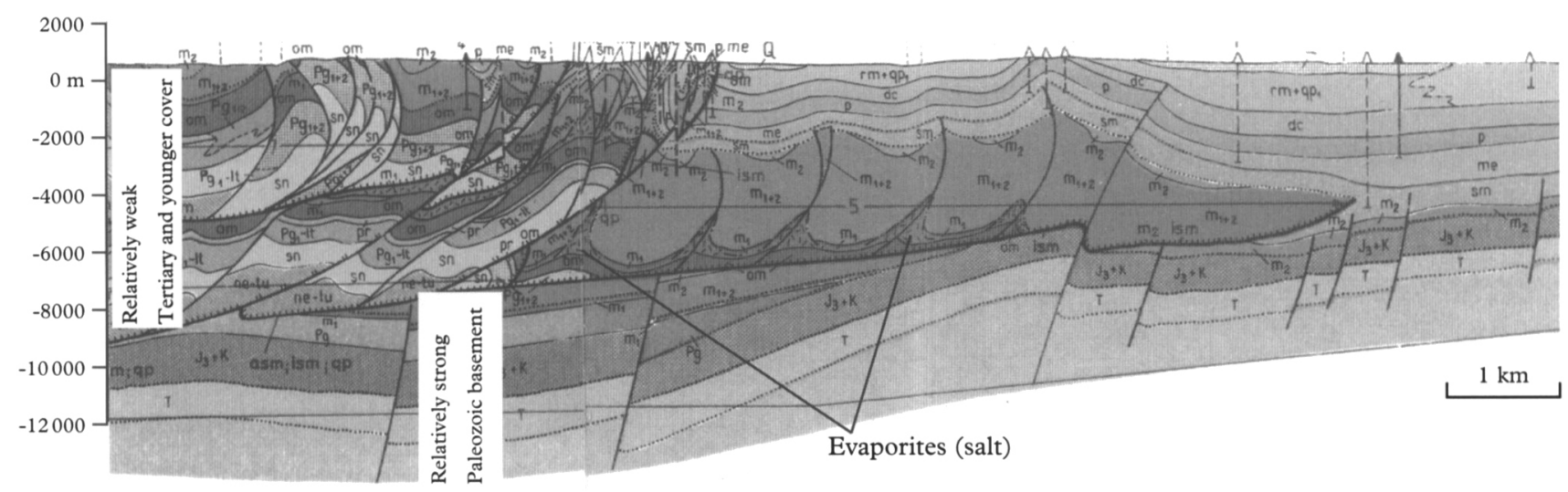

Fig. 7. NW-SE geological cross-section in central Rumania, based on 2-D seismic and well data (Stefanescu, 1984). The thrust belt moved in SE direction, initially over a salt decollement. As the salt horizon terminated in the southernmost part at the thrust-belt front, the thrust belt further back in the hinterland was reactivated and significant out-of-sequence thrusting took place due to the rapid change from low to high basal frictional resistance.

\section{A low-friction decollement and a basement high}

The critical distance at which the effect of a basement high can still be felt, depends on the frictional resistance at the decollement and the strength of the thrust-sheet rocks. A decrease in basal friction reduces the work needed to overcome basal shear stress. This enables transmission of stress for longer distances through a strong thrust sheet. The effect of the decollement can be demonstrated with multi-layer sandbox experiments. In the presence of a ductile substratum, the increase in thrust-sheet length due to the presence of a basement high is further enhanced (Fig. 10). A geological example from Romania illustrates the development of a thrust with a halite decollement over a basement high (Fig. 11).

Transport of the exceptionally long thrust sheet over the step in the basement requires more energy than the formation of an out-of-sequence thrust. As a result, the long thrust sheet breaks into shorter elements. Even though initially a very long thrust sheet has been formed, the long brittle sheet is not strong enough to support the stress build-up required for overthrusting once it has to move over the ramp, and it breaks up into smaller thrust sheets.

\section{Syntectonic sedimentation}

Syntectonic sedimentation affects the angle of the taper in two ways: sedimentation in front of the taper lowers the angle; at the same time, erosion at the crest does the same. In line with the argumentation presented above, this results in out-of-sequence thrusting due to continuous lowering of the taper to well below the critical angle.

In the Po river plain, northern Italy (Fig. 12),

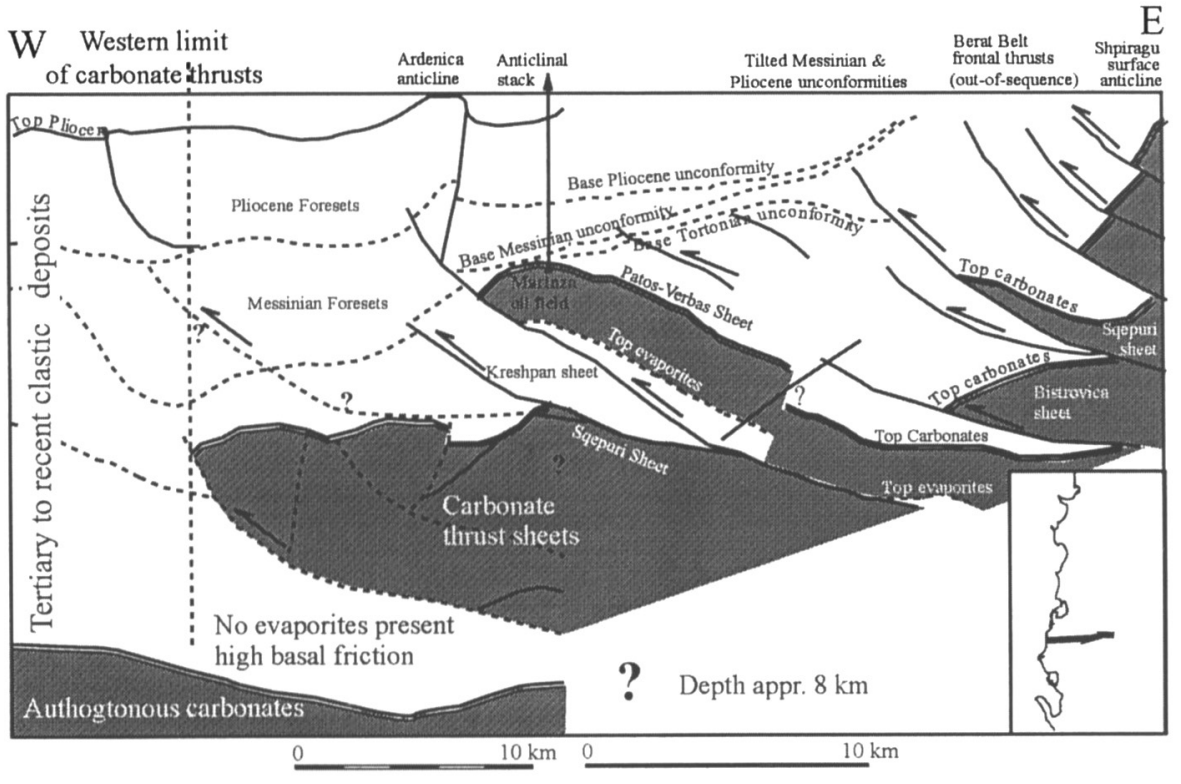

Fig. 8. 2-D regional seismic line, onshore southern central Albania. Sowing anticlinal stack of thrust sheets. Out-ofsequence thrusting has clearly taken place, deforming the unconformities on top of the stack. Strongly tilted unconformable contacts as seen on the seismic, can also be observed in the field. Thrust movement was from east to west. The dissappearance of the Triassic evaporites in the western part of the section caused the out-of-sequence thrusting. 

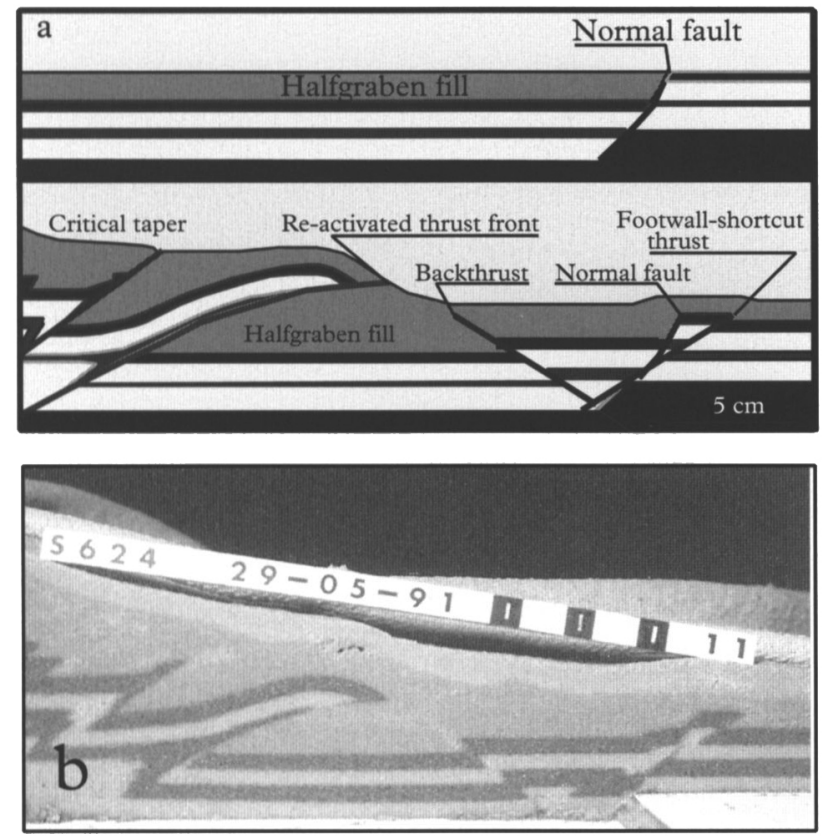

Fig. 9. Basement high with footwall shortcut and out-of-sequence reactivation. A basement high in the foreland is often a preferred site for thrust-fault nucleation and may lead to thrust sheets that are longer or shorter than normal. Normal faults parallel to a thrust front will not be reactivated by compression perpendicular to the strike; a footwall shortcut forms instead. Following the formation of the footwall shortcut thrust, the frontal thrust of the critical taper is often reactivated out of sequence in response to the additional work that is needed to continue forward movement of the thrust belt.

a: interpretation of thrusting perpendicular to a basement normal fault and a normal fault in the sediment cover, based on experiment S624.

b: cross-section of experiment S624.

thrusting developed initially in a normal piggy-back sequence, but was followed by out-of-sequence thrusting due to syntectonic sedimentation (Bally, 1983). Near the hinterland, the sedimentation rate was high.
This suppressed further thrusting and, together with continued tectonic loading in the hinterland, also resulted into strong downwarping of the basement, resulting in a 'frozen' position of the thrusts in this area. The wedge angle was reduced by the addition of sediments at the front and resulted in out-of-sequence thrusting in the wedge to regain the steeper equilibrium angle. This in turn led to erosion and a further increase in sedimentation rate during the Quaternary. Further to the front of the fold-and-thrust belt, the deformation process is less complicated and the effect of syntectonic sedimentation is more clearly demonstrated. The sedimentation rate during the Middle to Late Pliocene was not quite as high as in the hinterland area and most of the thrusts were reactivated out of sequence, some to the extent that they broke the surface, as indicated by eroded crests. Onlap in several small local depo-centres, characteristic for syntectonic sedimentation, is also well developed.

A sandbox experiment example and a seismic example from the Mardin Formation in Southeast Turkey display the same phenomena (Figs. 13, 14).

\section{The dynamic wedge-concept and prediction of out-of-sequence thrusting}

Although fold-and-thrust belts may move over an essentially horizontal decollement plane, most of them have geometries that do not conform to the simple assumption of a rectangular rock mass moving over a horizontal substratum. The overall mechanics are described better with the analogue of a wedge of snow or soil pushed up-dip in front of a bulldozer (Davis et al., 1984; Mulugeta, 1987; Huiqi et al., 1991; Storti \& McClay, 1995). This analogue has become known as the critical taper (or critical-wedge) theory. The angle

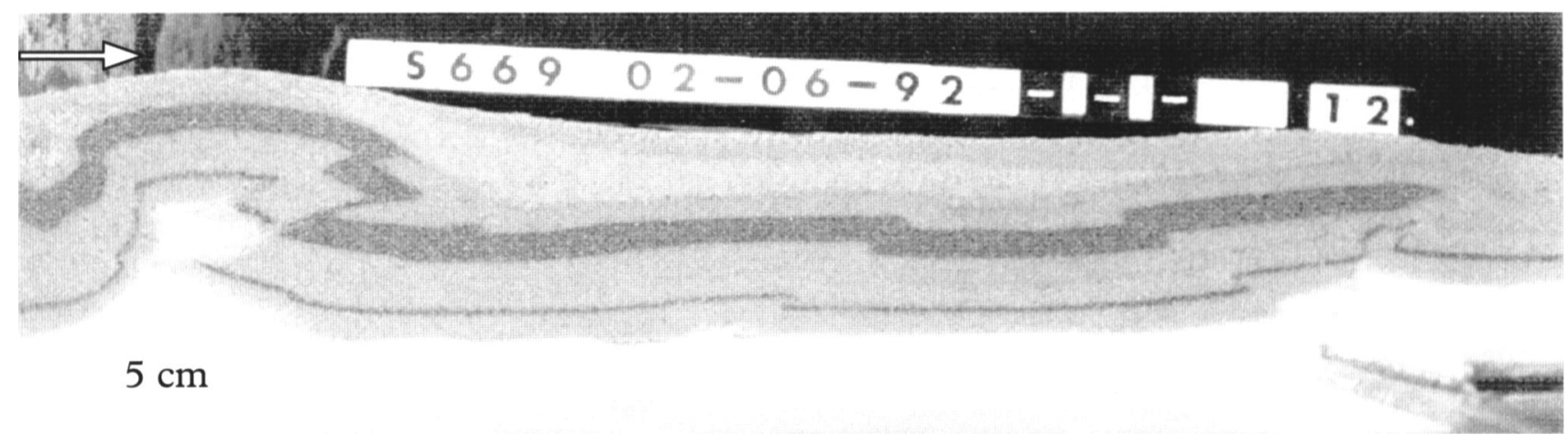

Fig. 10. Weak decollement with basement high, elongated thrust sheet and out-of-sequence thrusting. Thrusting over a basement high in the presence of a weak decollement can enlarge the thrust-sheet length considerably. In the experiment shown here, OWE was used as ductile decollement. The frontal thrust is located at the basement high, where it nucleated at the position of the normal fault in the sediment cover. The normal fault was not reactivated; a footwall shortcut formed instead. Subsequently, an out-of-sequence thrust divided the elongated thrust sheet into two. The extra stress, needed to move the long thrust sheet over the ramp, was more than the compressional strength of the sand and the thrust sheet broke into shorter segments. The top sand layer was added after deformation and before wetting the model, to protect the internal structures during wetting of the model for sectioning. 


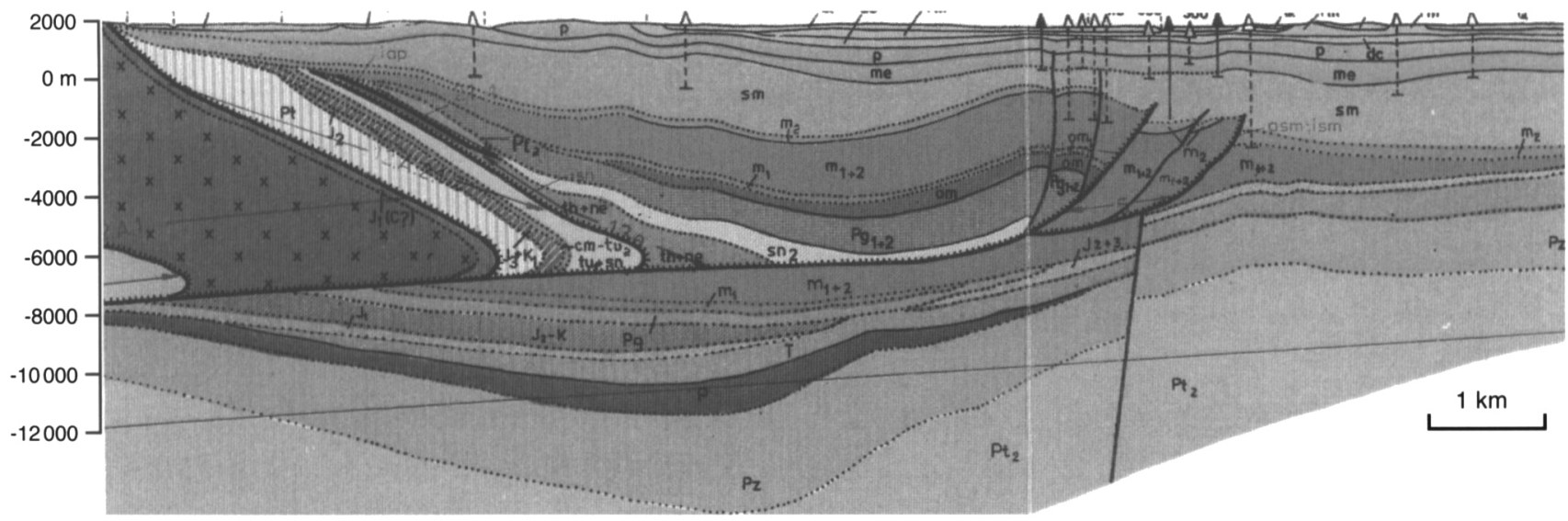

Fig. 11. NNW-SSE geological cross-section in central Rumania, based on 2-D seismic and well data (Stefanescu, 1984). The normal fault in the basement closest to the thrust front has affected the length of the thrust sheet, which is significantly longer than in other sections where the basement high is missing (as in, for instance, Fig. 7). The major thrust behind the frontal thrust moved out of sequence as indicated by the sediment pattern and unconformities above it. The overall structure closely resembles the sandbox experiment with a basement high (Figs. 9 and 10).

of the critical taper is determined by the compressive force in each segment of the wedge, being balanced by the frictional resistance of the part of the wedge in front of that segment. The horizontal compressive force at each point in the wedge is equal to the compressive strength integrated over the wedge thickness at the same position. This relationship is essentially the same as described by Hubbert \& Rubey (1959), expressing the maximum horizontal compressive force that can be sustained by the material of a rectangular block. The critical taper model explains why the thrust-sheet length, L, can exceed the maximum length as calculated using the principle of effective stress and the simplification of a rectangular block. A tapered thrust sheet of the same length as a rectangular block requires less horizontal force to induce sliding, mainly due to its lower mass and decreased gravity force towards the front.

A fundamental assumption behind the critical taper theory is that the strain rates associated with thrusting are so small that a balance of forces can be assumed. Although the strain rates are very small indeed, the examples discussed above demonstrate, however, that it is essential to consider the dynamics of thrust tectonics to understand the role of the faults in the deformation process. When the dynamics of this process are better understood, it is possible to predict fault geometries and the sequence of movements in thrust belts. A growing thrust belt is a dynamic system. Wedge equilibrium is maintained as long as the boundary conditions remain stable, but this requires changes in the wedge angle during the deformation process. Changes in the boundary conditions of the dynamic wedge will generally lead to changes in the angle of the wedge. These can often be predicted when the mechanical stratigraphy of the thrust sequence (including lateral variations) is known.

\section{Conclusions}

Changes in the dynamic equilibrium between stress and strain in a moving thrust belt are balanced by changes in the angle of the critical taper. This is achieved by out-of-sequence thrusting.

Sandbox experiments and natural examples demonstrate that changes in the boundary conditions defining the angle of the critical taper lead to adjustments of this angle by reactivation of existing faults and/or by out-of-sequence thrusting.

A critical examination of the boundary conditions of a fold-and-thrust belt and of changes in the boundary conditions during the deformation process enables predictions about the kinematics and geometry of the thrust belt.

\section{Acknowledgements}

The authors wish to thank Shell Research and Technical Services for permission to publish this paper. Discussions with Reini Zoetemeijer and critical reviews by Reini and Willem Nieuwenhuis significantly improved the manuscript.

\section{References}

Bally A.W. (ed.), 1983. Seismic expression of structural styles, a picture and work atlas. American Association of Petroleum Geologists (Tulsa).

Davis, D., Suppe, J. \& Dahlen, F.A., 1984. Mechanics of fold-andthrust belts and accretionary wedges: Cohesive Coulomb theory. Journal of Geophysical Research 89: 10087-10101. 


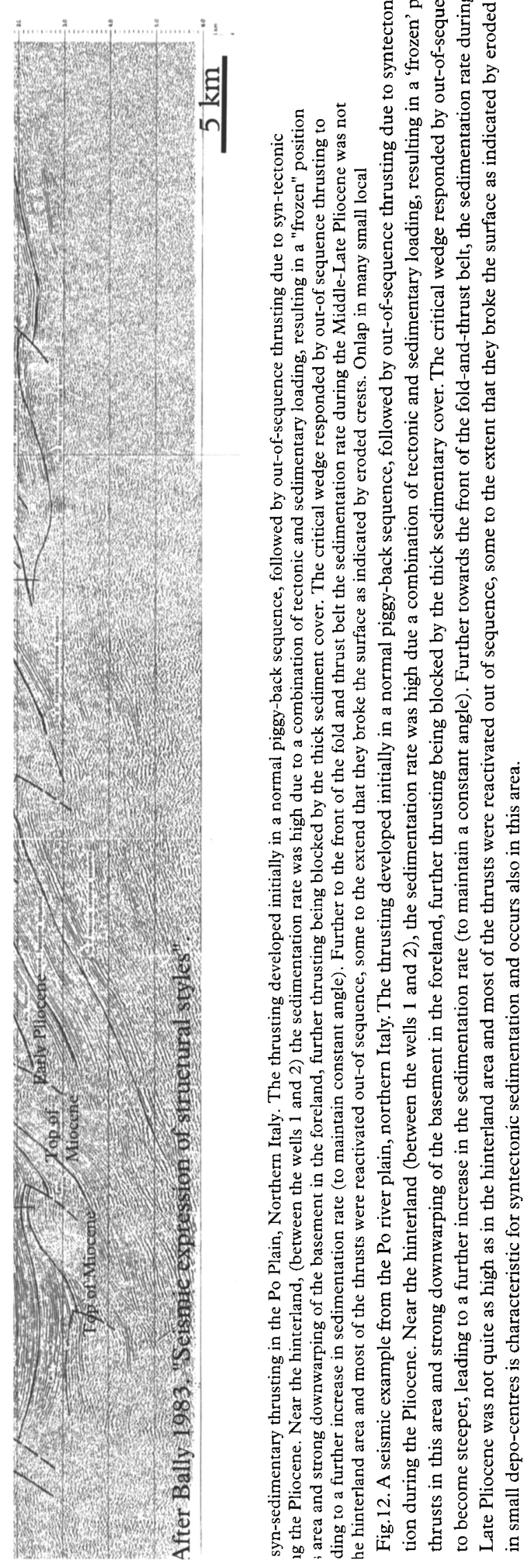

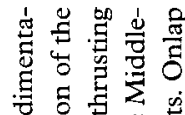

过艺

$4:$ to 0

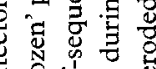

岁范

ॠ

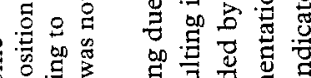

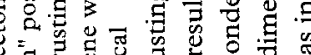

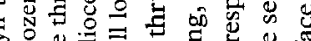

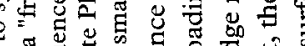

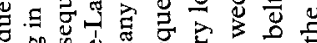

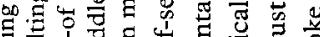

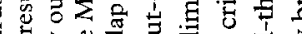

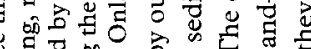

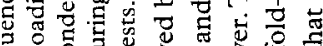

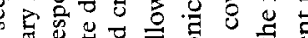

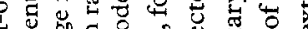

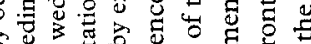

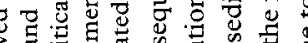

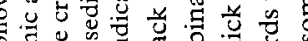

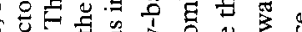

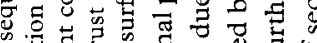

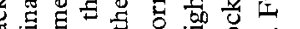

E

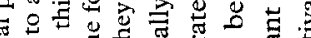

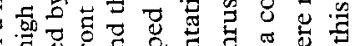

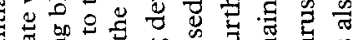

हैं के

讨

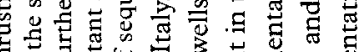

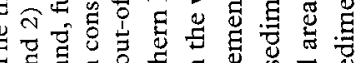

ज 5 द

(2)

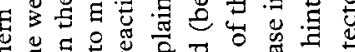

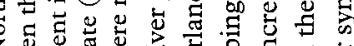

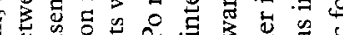

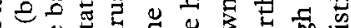

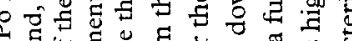

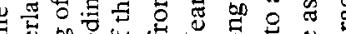

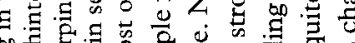

政

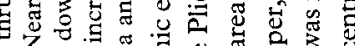

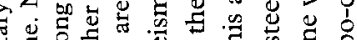

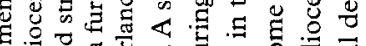

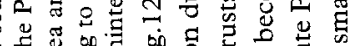

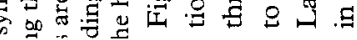

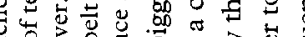

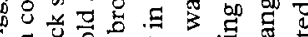

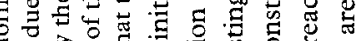

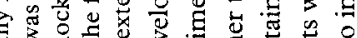

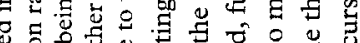

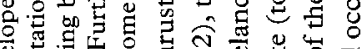

A

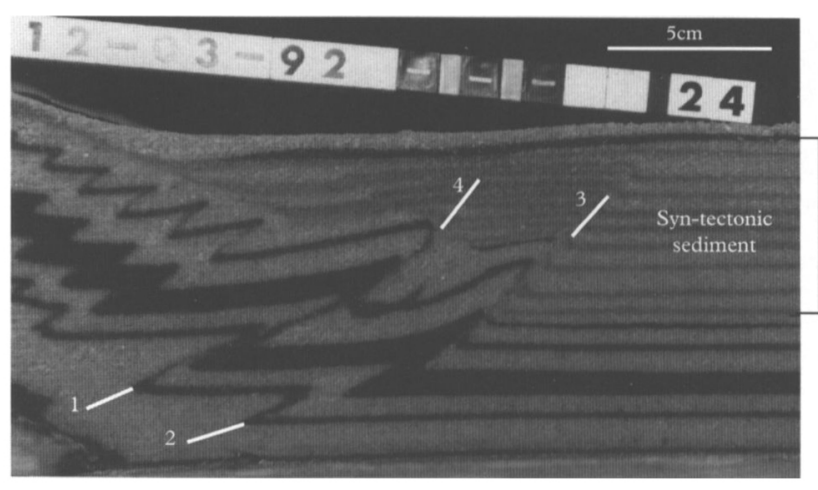

B

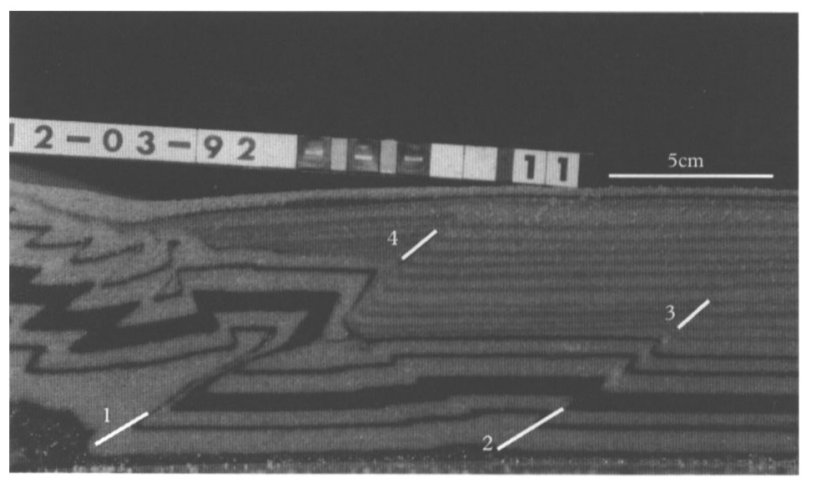

Fig. 13. Experimental examples of syn-tectonic sedimentation.

A: a high sedimentation rate fixes the thrust front. The faults curve upwards in cross-section; this results in rotation and onlap of the sediments onto the back of the thrust sheets. The thrust front is steep, reaching an angle of up to $60^{\circ}$ in sandbox experiments.

B: a lower sedimentation rate results in out-of-sequence thrusting and erosion of exposed crests (not seen in this experiment). A low-friction substratum (glass beads) enhances the effects. This experiment models the structural development as seen in the seismic section of Figure 14. Numbers indicate the sequence of thrust activity.

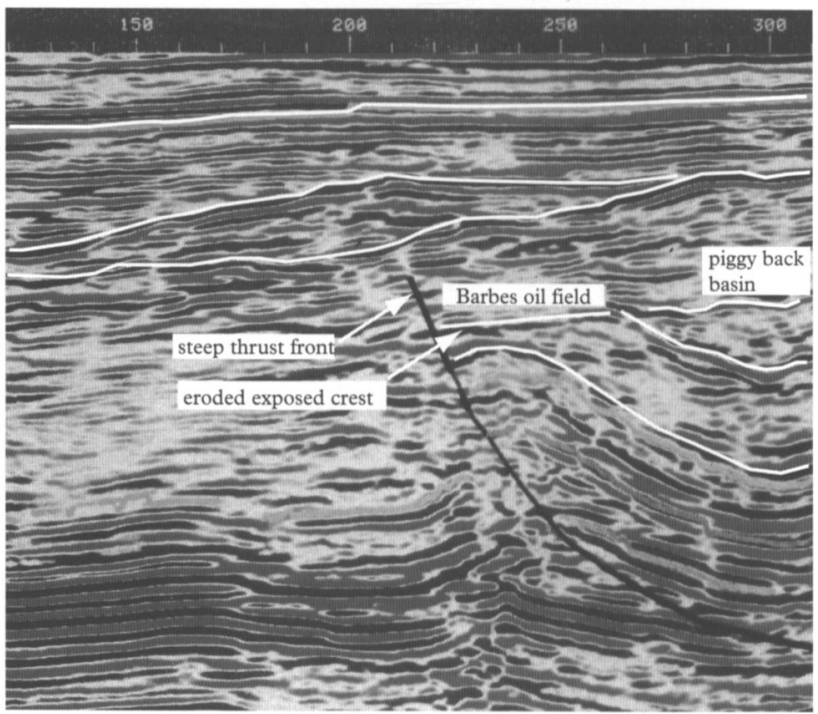

Fig. 14. Seismic example from a 3-D survey in SE Turkey, showing a high sedimentation rate, a steep high-angle thrust front, rotation and onlap onto the back of the thrust sheet, an eroded crest and some minor unconformities indicating neo-tectonic activity. 
Elliot, D., 1976. The motion of thrust sheets. Journal of Geophysical Research 81: 949-964.

Hardy, S., Duncan, C., Masek, J. \& Brown, D., 1998. Minimum work, fault activity and the growth of critical wedges in fold-andthrust belts. Basin Research 10: 365-373.

Hubbert, M.K. \& Rubey, W.W., 1959. Role of fluid pressure in mechanics of overthrust faulting. Part I. Geological Society of America Bulletin 70: 115-166.

Huiqi, L., McClay, K.R. \& Powell, D., 1991. Physical models of thrust wedges. In: McClay, K.R. (ed.): Thrust tectonics. Chapman and Hall (London): 71-81.

Jaeger, J.C. \& Cook, N.G.W., 1979. Fundamentals of rock mechanics. Chapman and Hall (London) science paperbacks 18: 593 pp.

Mandl, G., 1988. Mechanics of tectonic faulting. Elsevier (Amsterdam): $407 \mathrm{pp}$

Mandl G. \& G.K.Shippam 1981 Mechanical model of thrust sheet gliding and imbrication. In: McClay, K.R. \& Price, N.J. (eds.): Thrust and nappe tectonics. Geological Society (London) Special Publication 9: 79-97.

Mitra, S., 1986. Duplex structures and imbricate thrust systems: geometry, structural position and hydrocarbon potential. American Association of Petroleum Geologists Bulletin 70: 10871112.

Mitra, G. \& Boyer, S.E., 1986. Energy balance and deformation mechanisms of duplexes. Journal of Structural Geology 8: 291304.
Moore, J.C., 1989. Tectonics and hydrogeology of accretionary prisms: role of the decollement zone. Journal of Structural Geology 11:95-106.

Mulugeta, G., 1987. Modelling the geometry of Coulomb thrust wedges. Journal of Structural Geology 10: 847-859.

Nieuwland, D.A., Urai, J. \& Knoop, M., 1999. In-situ stress measurements in model experiments of tectonic faulting. In: Lehner, F. \& Urai, J. (eds.): Aspects of tectonic faulting. Springer Verlag (Berlin), in press.

Stefanescu, M. (ed.), 1984. Elaborarea profilelor, scara $1: 200.000$ pentru completarea imaginii geologice a teritoriului R.S. Romania. Institutul de Geologie si Geofizica (Bucuresti).

Storti, F. \& McClay, K.R., 1995. Influence of syntectonic sedimentation on thrust wedges in analogue models. Geology 23: 9991002.

Suppe, J., 1985. Principles of structural geology. Prentice Hall (Englewood Cliffs, NJ): $536 \mathrm{pp}$

Verschuren, M., Nieuwland, D.A. \& Gast, J., 1996. Multiple detachment levels in thrust tectonics: sandbox experiments and palinspastic reconstruction. In: Buchanan, P.G. \& Nieuwland, D.A. (eds.): Modern developments in structural interpretation, validation and modelling. Geological Society (London) Special Publication 99: 227-234.

Willett, S.D., 1992. Dynamic and kinematic growth and change of a Coulomb wedge. In: McClay, K.R. (ed.): Thrust tectonics. Chapman and Hall (London): 19-32. 